\title{
FREQUENCY OF DEPRESSION IN PATIENTS WITH TYPE 1 AND TYPE 2 DIABETES MELLITUS.
}

1. MBBS, FCPS

Senior Registrar Psychiatry

Gajju Khan Medical College, Swabi.

2. MBBS, FCPS

Assistant Professor Psychiatry

Lady Reading Hospital, Peshawar.

3. MBBS, FCPS

Assistant Professor Psychiatry Mohtarma Benazir Bhutto Shaheed,

Medical College Mirpur AJK.

4. MBBS, FCPS

Professor Institute of Psychiatry Benazir Bhutto Hospital, Rawalpindi.

5. MBBS, MRCPsych

Ex Professor Institute of Psychiatry

Benazir Bhutto Hospital, Rawalpindi.

Correspondence Address:

Dr. Zainab Nawaz

House No. 45, Street No.1, Gulshan

e Alhuda,

Park Road, Chak Shahzad, Islamabad. drzainab@ymail.com

Article received on:

10/02/2020

Accepted for publication:

$18 / 04 / 2020$

\section{Zainab Nawaz ${ }^{1}$, Adil Afridi ${ }^{2}$, Shakeel Asif ${ }^{3}$, Asad Tamizzudin Nizami ${ }^{4}$, Fareed Aslam Minhas ${ }^{5}$}

ABSTRACT... Objectives: To determine the frequency of depression in patients with diabetes mellitus and comparison of the frequency of depression in patients with diabetes mellitus (type1 \& 2). Study Design: Descriptive Cross-Sectional Study. Setting: Diabetic Clinic of Benazir Bhutto Hospital, Rawalpindi. Period: From $6^{\text {th }}$ June $-5^{\text {th }}$ December 2016. Material \& Methods: A total of 200 patients with diabetes mellitus were inducted in the study through Diabetic Out Patient Department at Benazir Bhutto Hospital, Rawalpindi. Patients screening was done by using ICD10-criteria \&Beck Depressive inventory (depression diagnosis and severity assessment). Designed proforma was used for demographic details and variables. The data was analyzed using SPSS version 16.0. Depression frequency and severity was calculated. Chi Square test was applied depression and categorical variables associations. Results: Frequency of depression in the study sample came out to be $57 \%$ (114 out of 200 patients). Results concluded that 26 patients have mild depression (13\%), $38(19 \%)$ moderate depression, and $24(12 \%)$ with severe depression. There is no significant difference in frequencies of depression in terms of type of Diabetes mellitus i.e. T1DM vs T2DM (39\% vs $61 \%$, P value $>0.05$ ). Monthly income and BMI were factors leading to mental distress. Conclusion: Many of the patients with diabetes have co-morbid depression. Screening and appropriate treatment of depression should be part of the management plan of all patients having diabetes.

Keys words: Comparison, Categorical Variables, Depression, Diabetes Mellitus, Frequency, Mental Distress.

Article Citation: Nawaz Z, Afridi A, Asif S, Nizami AT, Minhas FA. Frequency of depression in patients with Type 1 and Type 2 diabetes mellitus. Professional Med J 2020; 27(6):1291-1296. DOI: 10.29309/TPMJ/2020.27.06.4565

\section{INTRODUTION}

Patients having chronic and remitting physical illnesses have chances of 2-3 folds increased ratio of co-morbid major depression as compared to the patients of same age and sex in primary care. ${ }^{1,2}$

According to World Health Organization (WHO) estimation, the numbers of people with diabetes are increasing day by day and approximately this ratio would rise to 300 million by year $2025 .{ }^{3}$ In underdeveloped countries like Pakistan this ratio was approximately 6.6 million in year 2012 alone while is also progressively showing a sudden steep, making it the $10^{\text {th }}$ largest nation suffering with disbetes. ${ }^{4}$

The WHO has predicted that depression would lead from $4^{\text {th }}$ rank to $2^{\text {nd }}$ most vulnerable illness worldwide till 2020. ${ }^{5}$ According to the WHO there are 350 million cases of major depressive disorder globally, with the highly affected population of adults between the ages 25 to 34 years. The global point prevalence of depression in $4.4 \%$, with some gender difference female to male ratio of 5.5\%-3.2\%. ${ }^{6}$ From Pakistan a systematic review of various studies showed a depression and anxiety prevalence in the range of $34 \%$ done in $2004 .^{7}$

Depression is associated with diabetic complications, co-morbidities along with the severe psychological distress. Individuals with diabetes (type1\&2) have about a 2-fold increased risk for depressive illness and anxiety symptoms, affecting one (1) of every 10 diabetic patients. ${ }^{8}$

Current epidemiological evidence suggests that 
at least $1 / 3$ of the people with diabetes (type 1\&2) are suffering from multiple mild, moderate or severe degrees of depressive episodes. In year 2007 the overall 1year prevalence depression symptoms in individuals with diabetes was estimated to be $9.3 \%$. In South Asian studies, it has been reported that there is 2-5-fold increase in the prevalence rates of depression in people with diabetes in comparison to people without diabetes mellitus. ${ }^{2}$ Depression with diabetes ratio is $15 \%$ as compared to $5 \%$ amongst those without diabetes according to Pakistani community research studies. ${ }^{3}$

Current data of studies is unable to reveal any positive association of genetic factors between type 1\&2 diabetes and depressive disorder. ${ }^{9,10}$

A systemic review revealed that the co-morbidity of depression with diabetes may lead to 1.5 -fold increase in risk of mortality rate as compared to normal population. Fourvariousstudiesconcluded that Co-morbid depression and diabetes may lead to an approximately $20 \%$ higher risk of death due to cardiovascular mortality. In the year 2013 approximately 5.1 million people of age 20 -79 years died from diabetic complications, that accounts for $8.4 \%$ of globally all causes of death noticed among the population in this age group. ${ }^{11}$ In a study (Katon et al) conducted in US, reported that over a period of 2 years, co-morbid diabetes and depression had a $36-38 \%$ increased risk for all-cause mortality. ${ }^{12,13}$

Complications associated with co-morbid depression and diabetes are reduced compliance to medication, poor quality of life, gross distress in routine activities, decreased self-care, less physical activity, poor glycemic control, increased utilization of health care resources, and elevated risk of diabetes's complications, as well as rise in mortality rates so it is imperative to assess and treat depression in order to achieve optimal treatment goal. ${ }^{14}$

The main outcome measure was frequency of depression and comparison of depression (frequency) in patients with type 1 \& type 2 diabetes mellitus.

\section{MATERIAL \& METHODS}

The design of the study was descriptive crosssectional study and was conducted at Diabetic Clinic of Benazir Bhutto Hospital, Rawalpindi, from $6^{\text {th }}$ June $-5^{\text {th }}$ December 2016. Sample size was calculated by using WHO sample size calculator turned out to be 200 .

Inclusion Criteria

1. Patients aged between 18 to 60 years.

2. Diagnosed cases of diabetes mellitus either type1 or type 2 diabetes mellitus.

3. Capable of giving informed consent to this study.

\section{Exclusion Criteria}

1. Patients with any Neurodegenerative brain disease i.e. Alzheimer disease, Parkinson disease or with stroke (CVA).

2. Patients unable to communicate.

\section{RESULTS}

The mean age in our study sample was 45.90 (S.D \pm 11.053$)$, with age range of $18-60$ year. The sample data consisted of $56 \%(n=112)$ women, and $44 \%(n=88)$ male. Out of 200 patients $40.5 \%$ $(n=81)$ had type 1 diabetes while $59.5 \%(n=119)$ had type 2 diabetes mellitus.55.5\% $(n=111)$ of patients had BMI within normal range. 5.5\% $(n=$ 11) were underweight while $28.5 \%(n=57)$ were overweight. Obese patients were $10.5 \%(n=21)$.

Table-I shows that among the participants, $56 \%$ $(n=152)$ had no depression, 13\% $(n=26)$ had mild depression, 19\% $(n=38)$ had moderate depression and $12 \% \quad(n=24)$ have severe depression. While Table-II reveals that female have more depression $n=112(56 \%)$ as compared to males. Table-III shows association between depression severity and monthly income, these findings showed that people with average income (10000-20000) have maximum depression and prevalence is almost $45.5 \%$ while only $5 \%$ depression is noticed in person with minimal or no income ( $P$ value less than 0.05 considered significant) Table-III shows participants with BMI in normal range have maximum prevalence of depression $n-111(55.5 \%)$ while participants have BMI less than 18(underweight) have minimum 
chance of depression $n-11(5.5 \%)(P$ value less than 0.05 considered significant).

\begin{tabular}{|c|c|c|}
\hline $\mathbf{N}=\mathbf{2 0 0}$ & Severity of Depression on BDI Scale & Frequency Percentage \\
\hline 152 & No depression $(1-9)$ & $56 \%$ \\
\hline 26 & Mild depression (10-18) & $13 \%$ \\
\hline 38 & Moderate depression (19-29) & $19 \%$ \\
\hline 24 & Severe depression (30-63) & $12 \%$ \\
\hline
\end{tabular}

Table-I. Showing the distribution of sample with regards score on Beck Depressive Inventory Scale for Depression frequency.

\begin{tabular}{|l|c|c|c|c|c|c|}
\hline \multicolumn{2}{|c|}{} & \multicolumn{9}{|c}{ Total BDI Score } \\
Depression & $\begin{array}{c}\text { Mild } \\
\text { Depression }\end{array}$ & $\begin{array}{c}\text { Moderate } \\
\text { Depression }\end{array}$ & $\begin{array}{c}\text { Severe } \\
\text { Depression }\end{array}$ & Total \\
\hline \multirow{2}{*}{ Gender } & Male & 49 & 9 & 19 & 11 & 88 \\
\hline & Female & 63 & 17 & 19 & 13 & 112 \\
\hline & & 112 & 26 & 38 & 24 & 200 \\
\hline
\end{tabular}

Table-II. Association between severity of depression and gender.

\begin{tabular}{|c|c|c|c|c|c|c|c|}
\hline & & \multicolumn{4}{|c|}{ Cross tabulation } & \multirow{3}{*}{ Total } & \multirow[b]{3}{*}{ Frequency $\%$} \\
\hline & & \multicolumn{4}{|c|}{ Total BDI score } & & \\
\hline & & $\begin{array}{c}1-9 \\
\text { No } \\
\text { Depression }\end{array}$ & $\begin{array}{c}10-18 \\
\text { Mild } \\
\text { Depression }\end{array}$ & $\begin{array}{c}19-29 \\
\text { Moderate } \\
\text { Depression }\end{array}$ & $\begin{array}{c}30-63 \\
\text { Severe } \\
\text { Depression }\end{array}$ & & \\
\hline \multirow{6}{*}{$\begin{array}{l}\text { Monthly } \\
\text { income in } \\
\text { Rupees }\end{array}$} & no income & 5 & 2 & 3 & 0 & 10 & 5.0 \\
\hline & less than 10000 & 4 & 3 & 5 & 3 & 15 & 7.5 \\
\hline & $10000-20000$ & 43 & 14 & 21 & 13 & 91 & 45.5 \\
\hline & $21000-31000$ & 25 & 5 & 6 & 6 & 42 & 21.2 \\
\hline & $32000-43000$ & 15 & 1 & 2 & 1 & 19 & 9.5 \\
\hline & greater than 43000 & 19 & 2 & 1 & 1 & 23 & 11.5 \\
\hline \multicolumn{2}{|l|}{ Total } & 111 & 26 & 38 & 24 & 200 & 100 \\
\hline
\end{tabular}

Table-III. Association between Severity of Depression and Monthly income (frequency mentioned).

\begin{tabular}{|l|c|c|c|}
\hline & Chi-Square Tests & P-Value \\
\hline Pearson Chi-Square & Value & df & .023 \\
\hline P value less than 0.05 considered significant & $35.432^{\mathrm{a}}$ & 20 & \\
\hline
\end{tabular}

\begin{tabular}{|c|c|c|c|c|c|c|}
\hline \multicolumn{7}{|c|}{ Cross tabulation } \\
\hline & & \multicolumn{4}{|c|}{ Total BDI score } & \multirow[t]{2}{*}{ Total } \\
\hline & & $\begin{array}{c}1-9 \\
\text { No Depression }\end{array}$ & $\begin{array}{c}10-18 \\
\text { Mild Depression }\end{array}$ & $\begin{array}{l}\text { 19-29 Moderate } \\
\text { Depression }\end{array}$ & 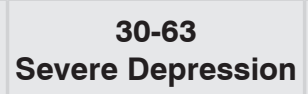 & \\
\hline \multirow{4}{*}{ BMI } & less than 18 underweight & 4 & 3 & 0 & 4 & 11 \\
\hline & $18.5-24.9$ normal & 65 & 12 & 22 & 12 & 111 \\
\hline & 25 or above overweight & 32 & 11 & 12 & 2 & 57 \\
\hline & 30 or more obese & 11 & 0 & 4 & 6 & 21 \\
\hline \multicolumn{2}{|r|}{ Total } & 112 & 26 & 38 & 24 & 200 \\
\hline
\end{tabular}




\begin{tabular}{|l|c|c|c|}
\hline \multicolumn{3}{|c|}{ Chi-Square Tests } & Df \\
\hline & Value & 12 & P-Value \\
\hline Pearson Chi-Square & $33.834^{\mathrm{a}}$ & 12 & .002 \\
\hline Where p-value less than 0.05 considered significant & & \\
\hline
\end{tabular}

\section{DISCUSSION}

The co-morbidity of depression and diabetes has been recognized as an emerging medical challenge that needs immense attention.

A meta-analysis (Anderson et al) ${ }^{15}$ having 42 studies with $n-21,351$, results showed that odds of depression in the diabetic group were twice that of the non-diabetic group and results did not effected by sex, types of diabetes, subject source, or assessment method. The prevalence of co-morbid depression was significantly higher in diabetic women than in diabetic men (28\%$18 \%$ respectively), in uncontrolled $(30 \%)$ than in controlled studies (21\%) and in clinical (32\%) than in community (20\%) samples.

In Pakistan, a study was conducted $^{16}$ that determine frequency of depression and anxiety in type 2 diabetic patients $(n-110)$. Diabetic patients were screened by using Urdu version of Hospital Anxiety and Depression Scale for depression and anxiety. HADS has 2 subscales: depression and anxiety, both with 7 items. Score of 9 was used as the cut-off point. Out of 110 patients, $52.7 \%$ reported as cases of depression, $46.6 \%$ were not $49 \%$ have anxiety symptoms and $50 \%$ does not have anxiety on this scale. Gender, area of residence, marital status education of the patients, treatment options for diabetes, duration of diabetes and treatment duration were not significantly related to control of diabetes. Female gender was significantly associated with presence of depression. Depression was statistically high in uneducated patients.

Roy and colleagues ${ }^{17}$ in Bangladesh conducted a study to determine the prevalence of co-morbid depression in patients with type 2 diabetes mellitus with n-483 from three diabetic clinics. Depression was assessed by using the World Health Organization-5 Well Being Index (WHO-5) and the Patient Health Questionairre-9(PHQ-9). On PHQ-9 prevalence of depression was $34 \%$ while on WHO-5 with audio questionnaire delivery method relieved $36 \%$. The frequency in our study is much higher i.e. $57 \%$. This difference could be due to use of different psychometric tool and that we included minimal depression in our study as well, i.e.13\%. If we exclude the minimal depression then the prevalence of depression would be $44 \%$. One of the results of their study was that depression was three times higher in females than males. This result was not replicated in our study where both genders showed almost equal prevalence of depression. Among other variables, Roy et al also found an association of monthly income with depression that is in line with our result. In our study, treatment options and diabetic complications are highlighted which needs further exploration and analysis. In Jordan a study was done with $n=649$ individuals by AlAmer and colleagues ${ }^{18}$ to reveal the association and frequency of depression in patients with Diabetes mellitus. Depression was measured by using Patients' Health Questionaire-8 (PHQ8 ). The prevalence was $19.7 \%$, lower when compared with our study, with higher prevalence again observed in female gender.

Thour $^{19}$ an Indian author done a cross sectional study which has found the prevalence of depression in diabetic patients (N-73) using Patient Health Questionnaire-9(PHQ-9) with type 2 variety. The depression was found in $41 \%$ of patients. Rural areas showed higher prevalence than the urban areas. There was no association of Age, sex, hypertension, duration of diabetes, with prevalence of depression. If we ignore minimal depression i.e. $13 \%$ in our study then our frequency of depression came out $44 \%$, this is quite close to results of Thour et al. Similarly, age and sex were not significantly related to depression in both the studies.

Larijani et $\mathrm{al}^{20}(\mathrm{~N}=375)$ found an association between type 2 diabetes, depression and glycemic control in a cross-sectional study. Beck 
Depressive Inventory was used for depression assessment and DSM-IV criteria used for depression diagnosis with $41.9 \%$ of patients have depressive disorder. Of these patients, major depressive disorder was confirmed in $23.7 \%$, dysthymic disorder in $9.3 \%$. The results are comparable with our study where the depression was found to be $57 \%$. The difference in result might be explained by difference in sample size and restriction of patients to type 2 only. Although there is no significant difference regarding prevalence of depression in both genders in our study, both monthly income and BMI are the factors that affect depression. Although our study did not look in to glycemic control, future studies should be aimed to consider this particular area.

\section{CONCLUSION}

Depression is a common co-morbid health problem in both T1DM and T2DM out patients. This study shows that there is a high prevalence of depression in patients with diabetes. All patients with diabetes and depression require adequate mental healthcare, hence integration of mental health services in primary care will be an important factor in preventing the development of depression among diabetes patients. In similar way, diagnosing and treating depression must be an essential component of the management plan of all patients with diabetes. Further studies are required in order to find out the relationship of depression and its impact on glycemic control, the development of diabetes complications and the management of diabetes.

Copyright(C) 18 Apr, 2020.

\section{REFERENCES}

1. Wayne J K. Epidemiology and treatment of depression in patients with chronic medical illness. Dialogues Clin Neurosci. 2011; 13: 7-23.

2. Ali S., Stone MA, Peters JL., Davies MJ, Khunti K. The prevalence of comorbid depression in adults with Type 2 diabetes: A systematic review and metaanalysis. Diabet Med. 2006; 23:1165-1173.

3. Zahid N, Asghar S, Claussen B and Hussain A. Depression and diabetes in a rural community in Pakistan. Diabetes Res Clin Pract. 2008; 79:124-7.
4. Kalra S, Peyrot M, Skovlund S. Second diabetes attitudes, wishes and needs (DAWN2) study: Relevance to Pakistan. J Pak Med Assoc 2013; 63:1218-9.

5. Snoek FJ, Bremmer MA, Hermanns N. Constructs of depression and distress in diabetes: Time for an appraisal. Lancet Diabetes Endocrinol. 2015; 3:450-60.

6. Ferrari AJ, Charlson FJ, Norman RE, Flaxman AD, Patten SB, Vos $T$ et al. The epidemiological modelling of major depressive disorder: Application for the Global Burden of Disease Study 2010. PLoS One. 2013; 8:e69637.

7. Mirza I, Jenkins R. Risk factors, prevalence, and treatment of anxiety and depressive disorders in Pakistan: Systematic review. BMJ. 2004; 328:794.

8. Andreoulakis E, Hyphantis T, Kandylis D, lacovides A. Depression in diabetes mellitus: A comprehensive review. Hippokratia. 2012; 16: 205-14.

9. Scherrer JF, Xian H, Lustman PJ, Franz CE, Mc Caffery J, Lyons MJ, Jacobson KC, Kremen WS. A test for common genetic and environmental vulnerability to depression and diabetes. Twin Res Hum Genet. 2011; 14:169-172.

10. Samaan Z, Garasia S, Gerstein HC, Engert JC, Mohan V, Diaz R, Anand SS, Meyre D. Lack of association between type 2 diabetes and major depression: Epidemiologic and genetic evidence in a multiethnic population. Transl Psychiatry. 2015; 5:e618.

11. Park M, Katon W J, Wolf F M. Depression and risk of mortality in individuals with diabetes: A meta-analysis and systematic review. Gen hospital psychiatry. 2013: 23; 217-22.

12. Katon, W., M.Y. Fan, J. Unutzer, et al., Depression and diabetes: A potentially lethal combination. J Gen Intern Med. 2008; 23: 1571-5.

13. Ismail K, Winkley $\mathrm{K}$, Stahl D, Chalder T, Edmonds $\mathrm{M}$. A cohort study of people with diabetes and their first foot ulcer: The role of depression on mortality. Diabetes Care. 2007; 6:1473-9.

14. Oladeji BD, Gureje O. The comorbidity between depression and diabetes. Curr Psychiatry Rep 2013; 15:390-3.

15. Anderson RJ, Freedland KE, Clouse RE, Lustman PJ. The prevalence of comorbid depression in adults with diabetes: A meta-analysis. Diabetes Care. 2001; 24:1069-78. 
16. Azad N, Gondal M, Abbas N, Shahid A. Frequency of depression and anxiety in patients attending a diabetes clinic. J Ayub Med Coll Abbottabad. 2014: 3; 323-7.

17. Roy T, Lloyd CE, Parvin M, Mohiuddin KG, Rahman M. Prevalence of co-morbid depression in out-patients with type 2 diabetes mellitus in Bangladesh. BMC Psychiatry. 2012; 12:123.

18. Al-Amer RM, Sobeh MM, Zayed AA, Al-domi, HA. Depression among adults with diabetes in Jordan: Risk factors and relationship to blood sugar. J Diabetes\Complicatins. 2011; 25:247-52.
19. Thour A, Das S, Sehrawat T, Gupta Y. Depression among patients with diabetes mellitus in North India evaluated using patient health questionnaire-9. Indian J Endocr Metab 2015; 19:252-5.

20. Larijani B, Bayat MK, Gorgani MK, Bandarian F, Akhondzade S, Sadjadi SA. Association between depression and diabetes. German J psychiatry. 2004; 3:62-65.

\begin{tabular}{|c|c|c|c|}
\hline \multicolumn{4}{|c|}{ AUTHORSHIP AND CONTRIBUTION DECLARATION } \\
\hline Sr. \# & Author(s) Full Name & Contribution to the paper & Author(s) Signature \\
\hline 1 & Zainab Nawaz & $\begin{array}{l}\text { Main Author ,Paper writing, } \\
\text { Data Analysis }\end{array}$ & Zainel Nawa 3 \\
\hline 2 & Adil Afridi & $\begin{array}{l}\text { Helps in data collection and } \\
\text { paper writing }\end{array}$ & A \\
\hline 3 & Shakeel Asif & Data collection & \\
\hline 4 & Asad Tamizzudin Nizami & Supervising the article & Assantanin zulutions \\
\hline 5 & Fareed Aslam Minhas & Supervising the Article & fawsed A. Aluhar. \\
\hline
\end{tabular}

